\title{
ORLANDO FALS BORDA, PEDAGOGO DE LA PRAXIS
}

NICOLÁS ARMANDO HERRERA FARFÁN

Universidad Surcolombiana

Neiva - Colombia 


\section{RESUMEN}

Orlando Fals Borda es sin lugar a dudas el investigador en ciencias sociales más importante de la historia reciente de Colombia y uno de los más prominentes pensadores latinoamericanos.

La obra de Orlando Fals Borda comienza a generarse en las preguntas y los temas de indagación social. Advierten los tres elementos de la ciencia como actitud mental: el "mimetismo intelectual", la necesidad de historizar los procesos sociales y el compromiso social concomitante con ellos. En el desarrollo del pensamiento-acción se va generando un proceso progresivo, consciente y decidido de ruptura epistemológica con los modelos europeos y norteamericanos de ciencia social, importados acríticamente e implantados irreflexivamente en las academias latinoamericanas. Esta discusión y ruptura lo llevan a plantearse la necesidad de construir un nuevo paradigma endogenético.

La educación superior debe propender a promover simultáneamente la búsqueda de nuevas metas (utopías) y la destrucción de viejos paradigmas. La implementación de un modelo dialéctico de la extensión, se advierte una necesidad inaplazable de "derribar los muros que aún separan, más de la cuenta a la universidad de la comunidad". La urgencia de romper el monopolio del conocimiento ya que es necesario incorporar a la dinámica propia de la vida universitaria el reconocimiento del Otro, representado en los estudiantes y en las comunidades y grupos de referencia. La conciencia ética es tener presente la existencia de los demás, no solo como simples estadísticas o depositarios de un saber. Conocer la realidad y conocerla bien es el prerrequisito para la transformación de un modelo de sociedad o la profundización de un anhelo histórico sobre la base de avances que hayan ocurrido en nuestros pueblos. Una universidad que no investiga es una tecnología de la dominación. En este proceso, la investigación ha de estar en el centro de la tarea universitaria. La alternativa es la puesta en práctica en el ámbito universitario del ritmo de reflexión-acción por el que apuesta la Investigación-Acción Participativa. Este proceso quizás pueda ayudarnos en varias direcciones: la primera, es que puede servir como vacuna para la arrogancia intelectual, con su actitud de diferenciación del trabajo intelectual y el trabajo manual; la segunda, que tal vez ayude a "encontrar" temas de investigación en los y las jóvenes para resolver la angustia de hacer una investigación para recibir sus títulos (aún en el pregrado); $y$, la tercera, que este encuentro permanente con la realidad promueva que los temas de indagación estén más próximos a la realidad social y no sólo salgan de la imaginación personal e individual del estudiante, entonces podremos construir una ciencia ligada a la realidad "real" y alejada de la realidad "científica". Es cierto que los tiempos han cambiado, encaramos un nuevo período de colonialismo (neocolonialismo) con un universo científico inconmovible. Los núcleos opositores y contrahegemónicos siguen luchando, aunque dispersos. Las angustias de los pueblos siguen a la orden del día y las lacerantes realidades están demandando una actitud creativa. Las aportaciones de Fals Borda al medio universitario pueden ayudar en la tarea emprendida por grupos dinámicos al interior de las instituciones siguen creyendo que la academia debe transformarse para beneficio de las mayorías y en el camino del mejoramiento de las condiciones de vida de la humanidad.

palabras claves: Orlando Fals Borda, sociología, pensamiento acción, educación superior, investigación-acción participativa.

\section{ABSTRACT}

Orlando Fals Borda is undoubtedly the most important research in social sciences in recent history of Colombia and one of the most prominent Latin American thinkers .

The work of Orlando Fals Borda begins to generate the questions and issues of social inquiry. Warn the three elements of science and mental attitude : the "intellectual mimicry" , the need to historicize the social processes and the concomitant social engagement with them. In the development of thought - action process is generating a progressive, conscious and decided epistemological break with European and American models of social science, imported uncritically and thoughtlessly implemented in Latin American schools. This discussion and break - lead him to raise is the need to build a new paradigm endogenético .

Higher education must tend to simultaneously promote the search for new targets ( utopias ) and the destruction of old paradigms. The implementation of a dialectical model of the extension, an urgent need to " break down the walls that still separate, more than necessary, to community college " is noted. The urge to break the monopoly of knowledge as it is necessary to incorporate the dynamics of university life the recognition of the Other, represented in students and communities and reference groups. Ethical awareness is be aware of the existence of the other, not only as mere statistics or depositories of knowledge. Knowing the reality and know it is the prerequisite for the transformation of a model of society or a historical deepening desire based on advances that have occurred in our villages. A research university is not a technology of domination. In this process, the investigation has to be in the center of the university task. The alternative is the implementation in universities rhythm of reflection and action by betting Participatory Action Research . This process may be able to help in several directions: the first is that it can serve as a vaccine for intellectual arrogance, his attitude differentiation of mental and manual labor, the second, which may help to "find" research topics young people in solving anxiety to do research for their titles (even at the undergraduate level ), and, third, that this ongoing encounter with reality promote the topics of inquiry are closer to social reality and not only out of personal and individual student imagination, then we can construct a science tied to the "real " reality and away from the "scientific " reality . It is true that times have changed, we face a new period of colonialism ( neo ) with an unshakable scientific universe. Opponents still fighting and counter nuclei, although scattered. The troubles of the people follow the agenda and heartrending reality are demanding a creative attitude. Fals Borda 's contributions to academia can help in the task undertaken by dynamic groups within institutions still believe that the academy must be trans formed to benefit the majority and in the way of improving the living conditions of mankind.

keywords: Orlando Fals Borda, sociology, thought, action, higher education, participatory action research. 
A Camilo Torres Restrepo, pedagogo de la ética y el ejemplo

Intelectual es el trabajador del pensamiento (...) aquel que empuña la pluma para combatir las iniquidades, como otros empuñan el arado para fecundar la tierra, o la espada para libertar a los pueblos, o los puñales para ajusticiar a los tiranos. Julio Antonio Mella

\section{Provocación}

Orlando Fals Borda es sin lugar adudas el investigador en ciencias sociales más importante de la historia reciente de Colombia y uno de los más prominentes pensadores latinoamericanos. Sociólogo, fundador del Departamento de Sociología de la Universidad Nacional de Colombia en 1959 (luego convertido en Facultad), fue uno de los pioneros en la búsqueda de una ciencia social latinoamericana, integradora y dinámica, que tuviera los colores de nuestras montañas, los sabores de nuestros valles y los acentos y ritmos de nuestras gentes.

Quizás para algunos y algunas estudiantes e investigadoras jóvenes el nombre y la figura de Orlando Fals Borda sea más bien espectral. Tal vez nunca han escuchado de él en las aulas de clases y mucho menos hayan tenido acceso a una lectura cercana de su obra o de sus postulados. Sin duda en círculos académicos más reducidos como las facultades de ciencias sociales y en las escuelas de sociología su nombre pueda tener aún algún tipo de resonancia.

La verdad sea dicha, acercarse a este tipo de pensadores e intelectuales vernáculos es una combinación de "arqueología" contemporánea y de "coraje". "Arqueología" porque sus textos no circulan con frecuencia y recurrencia en los medios académicos y su detección, búsqueda y lectura se hace desde una angustia previa, muchas veces solitaria; y "coraje", porque una vez que lo lees no puede dejar de dolerte emocionalmente cada línea que atraviesa su argumentación porque son golpes directos al ego, a la soberbia intelectual, a la "supremacía" de la razón instrumental... En una academia cada vez más "arrojada a los brazos del mercado mundial" -por no decir "postrada a los pies"-, engolosinada con los modelos pedagógicos, teóricos, metodológicos y evaluativos venidos de Europa y Estados Unidos -a los que se considera "de avanzada"- y enferma de la fiebre de "las acreditaciones y certificaciones de la calidad", ciertos nombres y pensamientos siguen causando prurito.

En el presente documento acercaré una reflexión acerca de la perspectiva que tenía Orlando Fals Borda sobre la educación superior, esto es, cómo concibe la universidad, cuál es la crítica y cuáles los retos. Convencido de que los conocimientos y la producción científica no son genialidades salidas de la chistera de un pensador o pensadora excepcionales, cono un mago que hace aparecer un conejo, desarrollaré este proceso en cuatro momentos. En el primer (1) momento abordaré una descripción rápida sobre las raíces del pensamiento de Orlando Fals Borda; en el segundo (2) describiré cuál fue el camino que recorrió el maestro en la construcción de su pensamiento y ética, ubicando algunos períodos para facilitar la comprensión; el tercer (3) momento se centra en las rupturas hechas por Fals Borda respecto del paradigma dominante (también llamado "hegemónico") en las ciencias sociales. Sobre la base de estos tres momentos (raíces, camino y rupturas) puedo acercar en el cuarto (4) momento las "claves" falsbordianas para la educación superior. Finalmente, dedicaré algunas breves líneas para una reflexión de cierre. 


\section{Raíces del pensamiento de Orlando Fals Borda}

Se pueden proponer cuatro raíces del pensamiento de Fals Borda, estos son: (a) su nicho cultural-ambiental, (b) la espiritualidad, (c) la formación científicohumanística y (d) su encuentro con la realidad histórica.

a) Nicho cultural-ambiental. Como él mismo lo repitió hasta el cansancio, su lugar simbólico y cultural lo constituye la costa caribe colombiana, una de las regiones mágicas del país, caracterizada por lo que él mismo llamó la costeñidad, esto es un "ethos de tolerancia y paz [y un] ambiente plácido de la confianza mutua y del dejadismo, y de la informal y gozosa mamadera de gallo". Un ethos tolerante y expansivo amalgamado con un cultural del humor y la jovialidad, y del dejar hacer, pletórico de símbolos y alegorías populares (Fals Borda, 2013, pp. 21-23). El mismo Fals Borda denominará a esta cultura en la que él creció como la cultura anfibia y ribereña en su monumental obra Historia Doble de la Costa. Es el mismo nicho de Gabriel García Márquez.

De la mano de sus abuelas Cándida Álvarez y Anita Angulo no sólo bebió el cariño que le prodigaron, sino los elementos simbólicos de la cultura anfibia: "pues desde muy niño le transmitieron cuentos leyendas regionales" (Cubides, 1995, p. 3). Con las abuelas también compartió la lectura de novelas románticas, narraciones, biografías de héroes y tratados de historia. El asunto de la literatura fue reforzado por sus padres: su padre, un maestro de escuela, periodista e intelectual silvestre motivó las lecturas en Orlando regalándole los libros y dándole un ejemplo libresco y comunicador; su madre, por su parte, maestra y escritora, se destacó como una trabajadora social y líder comunitaria en Barranquilla, siendo una de las primeras mujeres de su ciudad en tener un programa de radio en los años treinta (Cubides, 1995, p. 3). Orlando siempre la recordó como " una persona muy inteligente, una literata realmente, autora de dramas y cantatas (...) que tenía mucha sensibilidad social" (Fals Borda, 2013, p. 25).

Del nicho descrito, Orlando rescata el "ethos" del Caribe, la simbología popular, el gusto por la literatura, la música, la historia y el arte, el diálogo como fórmula privilegiada de intercambio y secreto de la interacción social, así como la dimensión estética y festiva de la vida.

b) La espiritualidad. De la mano de sus padres y sus abuelas Orlando llegó a la Iglesia Presbiteriana, a la cual "se habían convertido sus padres desde el catolicismo para ejercer la fe de una manera más activa y profunda" (Cubides, 1995, p. 3). Allí se involucró más de lleno en los ámbitos de la música, especialmente el piano y el coro, en los cuales había comenzado a incursionar con sus abuelas, madre y primos. Fue quizás lo que más le atrajo de la Iglesia: la música (Fals Borda, 2013, p. 26).

Aquel ambiente de la Iglesia estaba impregnado de solidaridad, honradez, disciplina, desprendimiento económico e indulgencia; era un ambiente que promovía la expresión de los talentos particulares e impulsaba las formas organizativas y comunicativas, sobre todo de los más jóvenes a través del Centro Juvenil Presbiteriano (CJP) del cual Orlando se hizo director. Fals Borda siempre recordó que el CJP tenía una dinámica cultural y deportiva 
increíbles en donde "se representaban obras de teatro clásico español, exposiciones de pintura con la ayuda de Alejandro Obregón [luego reconocido artista plástico], actividades literarias con Álvaro Cepeda Samudio [reconocido posteriormente como connotado escritor]". Por medio de estas actividades no religiosas, Orlando logró que la Iglesia Presbiteriana "hiciera una proyección sobre la sociedad barranquillera y costeña (...) [en] una especie de iglesia laica muy abierta, muy tolerante y ecuménica" (Fals Borda, 2013 , p. 26) que permitía "mostrar otra faceta de la Iglesia, distinta a la labor evangelizadora o educativa [porque estimulaba] el talento de los jóvenes en distintas áreas del arte y la cultura".(Pérez Benavides, 2010, p. 47-48).

Además del influjo positivo hacia la gente humilde (Cubides, 1995, p. 3) y el ecumenismo, entendido como actitud, la Iglesia Presbiteriana le aportó a Orlando una ética social, entendida como "la manera de ver los procesos sociales dentro de una perspectiva trascendente o preocupación última (...) y las implicaciones que derivan para la conducta personal y social, incluyendo visiones de cambios necesarios en las relaciones sociales" que a lo largo de su vida se expresa en tres momentos: ética del altruismo, ética del compromiso y ética cristiana ecuménica. (CastilloCárdenas, 2010, p. 20-21) A pesar de lo dicho hasta ahora, como afirma Pérez Benavides "poco o nada se ha explorado el trasfondo religioso de Orlando Fals, trasfondo que tiene origen en su familia y en la Iglesia Presbiteriana de Colombia" (Pérez Benavides, 2010, p. 26).

La conjunción de lass dos primeras raíces (nicho y espiritualidad) pueden llegar a proponerse, incluso, como los "antece- dentes profundos del "sabor" dialogal y literario de su obra, y de la capacidad organizativa y participante de su vida intelectual" (Carreta, 2011).

c) La formación científico-humanística. Su primera decisión fue el ejército, donde aprendió "el sentido del orden, la disciplina y el compañerismo". (Cubides, 1995, p. 4) Sin embargo, haber bebido de las fuentes de la música, la literatura y el arte Ilevaron a Orlando lejos de los cuarteles, y partió para los Estados Unidos a estudiar Literatura Inglesa y Música. Y hacia el final de sus estudios tomó un curso de sociología que ofrecía un profesor a partir de un libro suyo.

Su regreso a Colombia coincide con su encuentro con la sociología. Orlando Fals Borda, como muchos de nosotros, quizás, encuentra su profesión por accidente al descubrir una vocación en el terreno de campo. Si su búsqueda humanística nace del seno de su hogar, su Iglesia y su contexto inmediato -su nicho-, la búsqueda académica en ciencias sociales sale de las experiencias con las comunidades, de la vivencia y la experiencia, y su primer acercamiento se da cuando el ministerio de educación nacional (de Colombia) estaba desarrollando un programa "piloto" auspiciado por la Naciones Unidas en Vianí (Cundinamarca). En este proyecto necesitaban un responsable de archivo y Orlando fue contratado para aquella labor siendo rápidamente despedido. Así lo describió él mismo:

\footnotetext{
"el ministro me dijo (...) Vaya y organice el archivo, pero por ninguna razón establezca ningún contacto con la gente del pueblo[; pero] yo llegué al pueblo y lo primero que hice fue hacerme ami-
} 
go del cura y le ofrecí ser su organista en la misa. Entonces el trabajo en el archivo lo organicé en 10 días y por ahí como a los ocho días llegó Ospina, mi jefe, vio el archivo organizado; pero lo primero que le dijeron era que yo había estado muy metido con el cura y con el alcalde y que iba a las tiendas a tomar cerveza. (...) Me echaron del primer puesto de sociólogo a los 20 días porque había establecido contacto con la gente, fue el comienzo realmente de mi carrera sociológica" (Fals Borda, 2013, p. 27).

En este contexto descubre un ejemplar del primer estudio sociológico moderno hecho en Colombia (en 1948) por el profesor norteamericano Lynn Smith en Tabio (Cundinamarca); en este libro constaba en el apéndice los formularios de las encuestas -que incluían los principios de la antropología física, entonces en boga- que se usaron para desarrollar el estudio. Las fichas del profesor Smith le sirvieron de guía a Orlando para adelantar la exhaustiva recopilación de datos que hizo a los campesinos de Saucío (Cundinamarca), mientras trabajaba como secretario bilingüe en la compañía Winston Brothers Company, que adelantaba la construcción de dos represas en la región. Fals Borda narró en una entrevista concedida a educadores populares sus inicios en la sociología, a la sombra de su trabajo como secretario bilingüe, de la siguiente manera:

\footnotetext{
"Me hice amigo de ellos, de dos o tres, me invitaron a sus casas, adquirí la costumbre de quedarme con ellos en sus casas cada fin de semana, hasta cuando una fa-
}

milia me adoptó de hijo y me mudé a vivir allá; una casa totalmente humilde, sobre tierra, techo de paja, sin puertas prácticamente. (...) Esa llegó a ser mi familia. Aprendí de todo lo que es la vida, me enseñaron desde cómo sacar la papa hasta cómo guiar los bueyes, el uso de la hoz (...) [i] empecé a hablar como ellos y bailar!, aprendí a tocar torbellino y bambuco, a tocar tiple y a cantar con ellos.

Allí empecé a acumular los datos. (...) Muchos años después los campesinos me contaron que había unos debates en las tiendas $y$ en las casas conjeturando quién era yo, que si era un comunista que había llegado a sacar datos, que cómo era tanta preguntadera, que cuántos hijos tenía, que cuántas mujeres. (...) hubo peligro de que me cerraran las puertas como comunista, porque se corría mucho esa bola, este es un comunista que viene quién sabe a qué, nos van a aumentar los impuestos de pronto... (...) Me presenté un día con una balanza para pesarlos, después me dijeron las resistencias a pisar esa balanza, porque si se pesaban era para pesar sus pecados y entonces no iban a entrar al cielo, que si lo pesaban en esta vida en la otra no los iban a pesar (Fals Borda, 2013, p. 28).

La información recolectada en el trabajo de campo de Saucío se convirtió en la puerta de entrada a la sociología académi$\mathrm{ca}$, pues luego viajó a Minnesota a hacer el máster en Sociología, y en la Florida 
terminó sus estudios de Doctorado. Su tesis se llamó El hombre y la tierra en Boyacá, pero fue editada como Campesinos de los Andes con un subtítulo muy sugerente "Bases para una reforma agraria", en la que se esfuerza por "destacar la pobreza y el problema del campo como elementos esenciales para explicar la situación de atraso de Colombia y la violencia actual" (Fals Borda, 2013, p. 30). El hábil y diestro manejo de los datos demográficos, etnográficos e históricos, le permitió a Orlando construir una filigrana que retrataba de manera aguda los modos de vida de los campesinos cundiboyacenses. Esta combinación de las perspectivas sociológica, histórica y antropológica elevó tempranamente (tenía 30 años) el nombre Orlando Fals Borda al pináculo de la ciencia social latinoamericana. Sin embargo, como asegura Gonzalo Cataño, su éxito también debe asociarse a la elección de temáticas socialmente relevantes. A lo largo de su carrera se esforzó por mostrar "que la sociología y sus procedimientos de investigación podían aclarar situaciones complejas y proponer soluciones a los numerosos problemas del país" (Cataño, 2008, p. 80-81).

Su paso por la formación científica en los Estados Unidos dejó en Orlando algunos aportes definitivos. Por un lado, "una sólida formación en los grandes maestros de la sociología anglosajona y europea" (Sánchez, 2008, p. 10) y, por otro lado, "la afirmación de una ciencia social rigurosa, empírica y teóricamente significativa [con] un especial cuidado por la objetividad y por el uso combinado de técnicas y métodos de investigación empírica, además de un particular interés por el potencial aplicado de la sociología a los problemas del país" (Cataño, 2008, p. 80). Una sociología rigurosa en lo metodológico con un pro- fundo contenido estructural-funcionalista y una marcada primacía del trabajo de campo. La formación que Orlando toma en Estados Unidos tiene un carácter científico-sensible y artístico-racional.

d) La realidadhistórica. Toda su formación estuvo atravesada por un encuentro con la realidad histórica, entendida esta como los hechos y acontecimientos propios de su tiempo. Orlando fue quizás muy consciente de esta implicación cuando escribió sobre la relación interdependiente entre los marcos científicos y los contextos geográficos, culturales e históricos concretos donde se desarrollan dichos marcos, quizás siguiendo, entre otros, a Berger y Luckmann cuando afirman que "aglomeraciones de realidad y conocimiento se relacionan con contextos sociales específicos" (Berger y Luckmann, 1979).

El telón histórico de las tres primeras décadas (1950-1970) lo representan las luchas de liberación del colonialismo y, con ellas, la emergencia del Tercer Mundo, la explosión del movimiento guerrillero y una inusitada radicalidad política unida a un derroche de heroísmo en América Latina inspirado en la Revolución Cubana; el movimiento literario del boom, acompañado del nuevo cine y la nueva canción, Viet Nam, la dictadura brasileña, la invasión norteamericana en República Dominicana (Fernández Retamar, 2006, pp. 103-104, 160). Se desarrolló el rock'n'roll con los Beatles y los Rolling Stones, y junto a ellos el movimiento hippie y el flower power. Se produce el movimiento de mayo (en París, Berkeley, México), la elección de Salvador Allende en Chile, el implante de la Doctrina de Seguridad Nacional con sus gendarmes históricos y, de su mano, la expansión de la criminalidad política y el Terrorismo de Estado en 
América Latina, del cual Orlando no fue ajeno.

En Colombia se da la transición de una larvada guerra civil de carácter bipartidista denominada como "La Violencia" (1948-1953) hacia un movimiento armado con perspectivas revolucionarias (1964Hoy) con un ínterin dictatorial (llamado por algunos como "golpe de opinión") encabezado por el General Gustavo Rojas Pinilla y una Junta Militar de transición (1953-1958) que luego dará origen a una figura política que consolida el poder de las minorías en Colombia: el Frente Nacional (1958-1974). En la década de los setenta emergen las luchas campesinas, y explota en todo su vigor el movimiento estudiantil, despertado una década anterior, los fenómenos de explosiones sociales en forma de paros cívicos y huelgas generales y el desarrollo de una ofensiva estratégica en términos militares y políticos de la utopía colectiva.

La década de 1980 es un período de recreación revolucionaria en América Latina, impulsado por el triunfo del Sandinismo en Nicaragua (1979) y la profundización de la lucha guerrillera de Centroamérica, como contrapeso de la estrategia de recolonización del continente por parte de los Estados Unidos, iniciado en el Cono Sur por medio de las dictaduras militares y profundizado en América Central bajo la estrategia de los Conflictos de Baja Intensidad. A la vez que se acompaña académica y militantemente las luchas se es testigo ocular de la represión y los ríos de sangre que vuelven a abrir canales en los campos del continente. En Colombia también se da la guerra sucia y con ella se pierde una generación entera de cuadros políticos y activistas conscientes y una posibilidad histórica de alcanzar la paz con justicia y dignidad.

Con la redacción de una nueva Constitución (1991), en la que Orlando participa activamente como asambleario, Colombia pasará la década de 1990 enfrentando el terror y la barbarie liderada por los narcotraficantes, las fuerzas armadas y sus horrendos engendros cómplices: los paramilitares. El movimiento insurgente, fortalecido en la década anterior sufre un golpe profundo en sus entrañas con los hechos internacionales (caída del muro de Berlín, derrota del sandinismo, invasión de $\mathrm{Pa}$ namá) y los acontecimientos nacionales (desarticulación de la Coordinadora Guerrillera "Simón Bolívar" y posterior desmovilización de los núcleos del M-19, el $E P L$, el PRT, el Quintín Lame y algunos reductos del ELN y las FARC-EP y la ofensiva paramilitar). Las guerrillas continuaron, quizás como coletazo del período anterior, una etapa de escalada (las FARCEP en lo militar y el ELN en lo político, principalmente), con signos de debilidad, y el país entero asistió al fenómeno de paramilitarización nacional, el cual, tras una década intensa de barbarie sin límites (1995-2005) y luego de reconfigurar el mapa político nacional "a sangre y fuego" ocupó los puestos claves del gobierno central (en el Ejecutivo y el Legislativo) que le garantizaron los marcos jurídicos de protección, impunidad y legitimación con el cual se abría un nuevo período de la historia nacional.

Álvaro Uribe Vélez y Juan Manuel Santos estaban llamados a ser los profetas del nuevo ciclo, enfrentados a un movimiento guerrillero debilitado militar y políticamente, como correlato de la represión al movimiento social y popular, y un proceso de unidad de las izquierdas democráticas 
que alcanzó su clímax entre 2003 y 2008, cuando apareció en la escena política el Polo Democrático Alternativo del cual Orlando Fals Borda fuera su presidente honorario hasta que la muerte lo encontró en su departamento el 12 de agosto de 2008.

De la realidad histórica Orlando Fals Borda beberá la savia popular con el que va construyendo el sentido último de la ciencia: la construcción de una herramienta poderosa para el cambio social que tenga en cuenta las realidades populares y privilegie un diálogo fecundo con las necesidades de las poblaciones.

\section{El camino de la ética y el pensamiento en Orlando Fals Borda}

Las tres etapas del pensamiento de Orlando Fals Borda propuestas por Gonzalo Cataño (2008, pp. 80-91).

-Sociología científica, sociología comprometida e Investigación-Acción- se vinculan plenamente con los "momentos éticos" que alude Castillo-Cárdenas (2010, pp. 16-21): la ética del altruismo, ética del compromiso y ética cristiana ecuménica. Veamos esta relación de etapas y momentos un poco más en detalle.

\section{Sociología científica (década de 1950 a}

1965): es la etapa "del empiricismo y la objetividad, libre de valores" (CastilloCárdenas, 2010, p. 16), de sus primeras experiencias con campesinos en Vianí y Saucío (Cundinamarca), sus estudios de sociología en Estados Unidos -que hemos indicado líneas arriba-, la fundación de la Facultad de Sociología de la Universidad Nacional de Colombia y sus esfuerzos por la articulación academia-gobierno (desde la Universidad Nacional de Colom- bia con los ministerios de Agricultura y Educación, y el Instituto Colombiano de Reforma Agraria, INCORA). Estaba convencido que "la ciencia estudiaba la realidad con instrumentos objetivos $y$ [que] la difusión de sus resultados podía promover una conciencia de las dificultades en los grupos políticos con influencia y capacidad decisoria [por eso quería] crear una comunidad de investigadores sobre fundamentos estables". (Cataño, 2008, p. 81-82) Fue el período de adhesión al desarrollismo a partir del cual se comprometió en los asuntos de la Acción Comunal y la Reforma Agraria, y sus primeros acercamientos con el fenómeno de La Violencia en Colombia (Villanueva, 1995, p. 93).

Como académico impulsó la publicación de la colección "Monografías Sociológicas" y la fundación de la Asociación Colombiana de Sociología que desarrolló los dos primeros congresos nacionales (1963 y 1967) y el séptimo latinoamericano (1964). Junto a estas tareas, continúo su dimensión investigativa en temas como la violencia, la educación, la modernización y la acción comunal (Cataño, 2008, p. 8283).

El alto concepto que tenía de la sociología norteamericana, unido al prestigio que ya tenía por sus publicaciones le permitieron convocar a intelectuales de aquel país a que se vincularan como "profesores visitantes" del departamento de sociología. También estuvieron por aquellas aulas, profesores europeos, invitados principalmente por Camilo Torres Restrepo. Estos intercambios "contribuyeron a crear en la novísima escuela de sociología (...) un clima de apertura y plura- 
lismo intelectuales poco frecuente en las universidades de América Latina" (Cataño, 2008, p. 82).

Un acontecimiento de primera importancia en esta etapa fue el intercambio, articulación y trabajo con Camilo Torres Restrepo no sólo porque fortaleció su dimensión ecuménica (Camilo era sacerdote católico) sino porque transitaron juntos el período de búsqueda de la eficacia científica de una sociología aplicada, inspirada en la praxis, que ayudara a mejorar las condiciones del entorno social. Esta búsqueda devino en la proposición de una ciencia rebelde y subversiva que busca elementos vernáculos y críticos, abandonando progresivamente la escuela positivista y funcionalista (cartesiana) con la que habían sido formados en Europa y Estados Unidos. Lo que en Camilo Torres prontamente se llamó "Amor eficaz", en Orlando Fals Borda se fue traduciendo progresivamente en "Investigación- Acción Participativa".

El aporte determinante de Camilo al proceso de Fals Borda lo constituye la noción (y ejemplo) de compromiso, cercano a la definición sartreana, esto es: "la acción o la actitud del intelectual que, al tomar conciencia de su pertenencia a la sociedad y al mundo de su tiempo, renuncia a una posición de simple espectador y coloca su pensamiento o su arte al servicio de una causa". (Fals Borda, 2013, p.188) En Camilo Torres el compromiso está "con las luchas populares, con la necesidad de transformación social [que] lo asume y lo transmite para su propia interpretación y luego [con la entrega de] su vida" (Fals Borda, 2013, pp. 33-34).

Camilo abrió una nueva trocha por la cual circuló Orlando con solvencia y suficien- cia: "la justificación de la sociología como ciencia rebelde y subversiva, puesta al servicio de la causa de la transformación real de América [encabezando] el movimiento de independencia cultural de aquél entonces, no sólo respecto de la herencia teórica (...) sino en relación con la orientación de la labor científica, que había de dirigirse más y más hacia la problemática colombiana" (Fals Borda, 2013, pp. 63-69). Refiriéndose a la influencia de Camilo Torres en su vida, Fals Borda asevera que el "ejemplo práctico o praxiológico de Camilo Torres; su vida y convicciones, la manera como él incidió en la historia de Colombia, [lo] afectaron bastante y [lo] obligaron a reorientar [sus] trabajos como sociólogo". (Cubides, 1995, p. 9)

En esta primera etapa, la intención de Orlando Fals Borda era la de sensibilizar a las élites, realizando estudios dentro de los cánones establecidos de la ciencia destinados en primer lugar al mundo académico, en segundo lugar a las élites políticas y en tercer lugar al pueblo (Vanegas, 2008, p. 15). Por eso se ha dicho que la ética vinculada a esta etapa (ética del altruismo), caracterizada por el desprendimiento y el servicio desinteresado confiando en que "el país y el mundo serían mejor[es] si cada uno devolviera a la sociedad el doble de lo que ha recibido de ella", es una ética que conducía al reformismo, (Castillo-Cárdenas, 2010, p. 21) alimentado por la Alianza para el Progreso, aquella estrategia norteamericana diseñada para detener las búsquedas radicales de los pueblos latinoamericanos y que vinculaba inversiones de agencias (como la AID) y fundaciones (como Ford y Rockefeller) a los esfuerzos de los estados en campos como el educativo. 


\section{Sociología comprometida (1965 a}

1970): En la obra de Orlando Fals Borda comienza a generarse un giro en las preguntas y los temas de indagación. Transita de "La Violencia" hacia las revoluciones y los fenómenos subversivos; de los aspectos culturalistas del campesinado a las luchas campesinas, de la veneración de la academia homeostática norteamericana y europea a la búsqueda de un latinoamericanismo anticolonialista. Además se incorporan nuevas indagaciones: la crisis de las sociedades latinoamericanas, el estudio de las anti-élites, el cambio social.

En esta etapa se advierten los tres elementos de la ciencia como actitud mental: el "mimetismo intelectual", la necesidad de historizar los procesos sociales y el compromiso social concomitante con ellos. (Vanegas, 2008, p. 14-15) Esta reflexión sobre la ciencia estaba enmarcada en la crisis de la sociología occidental, caracterizada "por la quiebra del funcionalismo como marco de referencia hegemónico" (Cataño, 2008, p. 86).

El "mimetismo intelectual" evidenciado en la repetición acrítica de modelos científicos con la finalidad de repetir o confirmar lo que se hace en otras latitudes, así como el riesgo a confundir "neutralidad valorativa" con objetividad científica, esto es confundir el rigor en el desarrollo del método y el uso de las técnicas y herramientas, con la neutralidad, asepsia, éticopolítico que se exige al investigador. A juicio de Fals Borda "todo analista interesado en los procesos actuales, aquellos que implican finalidad y propósito, pronto descubre que la noción de neutralidad se disuelve en la mente hasta volverse un predicado vacío" (Cataño, 2008, p. 84). La lucha contra el "mimetismo" adquiere la forma de lucha contra el colonialismo intelectual (Fals Borda, 1981) y la ciencia libre de valores (Cataño, 2008, p. 84)

La historización de los procesos sociales conlleva a la desnaturalización de lo que se tenía por establecido en torno al proceso social y al marco científico que se emplea. Tal como en su obra La subversión en Colombia (1967/2008) de lo que se trata es de captar las lecciones del pasado "para comprender el presente y orientar el futuro" (Cataño, 2008, p. 84).

El compromiso social sólo podría ser entendido como consecuencia del conocimiento científico de la realidad social frente a la cual no se puede asumir una posición neutral porque eso conllevaría la adhesión al statu quo. En Orlando Fals Borda era evidente que el científico era un miembro activo de la sociedad, y como tal estaba conminado a tomar posiciones ante las realidades sociales lacerantes, escindidas y en permanente disputa, pues "los sectores empobrecidos esperan de él un diagnóstico de la sociedad en transición y una elección del mejor camino para alcanzar los anhelos de igualdad y justicia sociales" (Cataño, 2008, p. 84).

El asunto de concebir la ciencia como actitud mental estaba evidenciado incluso en la elección de los temas de investigación: cuanto más alejados de los problemas acuciantes más evidente era la orientación conservadora y reaccionaria del científico, y más esclarecidas quedaban las inclinaciones y los valores que guiaban su accionar (Cataño, 2008, p. 86). Ligado a esto estaba la necesidad de vincular el trabajo intelectual de escritorio con el trabajo de campo, "pues el contacto con la realidad es esencial" (Vanegas, 2008, p. 17). 
A diferencia de la sociología científica en la sociología comprometida se busca que los resultados de las investigaciones retornen a las personas que los producen, más allá de la comunidad científica y las élites. El investigador se concibe acá como un mediador que ayuda "a aflorar el pasado, las tradiciones más queridas y las luchas y experiencias que en otros tiempos promovieron la afirmación y el progreso humano" (Cataño, 2008, p. 87). Es una etapa donde busca un fundamento institucional y académico, creando el Programa Latinoamericano para el Desarrollo (PLEDES), que funcionó entre 1964 y 1969 y, que permitió "un acercamiento a las contribuciones de la sociología latinoamericana, muy sensibles al marxismo en aquellos años" en una época de gran florecimiento intelectual en la región (Cataño, 2008, p. 85-86). Si en la sociología científica convocó recurrentemente a los intelectuales norteamericanos y europeos, en la sociología comprometida convocó a los sociólogos latinoamericanos rebeldes de la época y atesoró para sí, de su antigua formación anglosajona, sólo a los pensadores afines a la crítica, el inconformismo y el extrañamiento con las condiciones de vida imperantes (Cataño, 2008, p. 85).

Los procesos sociales se comienzan a agudizar en Colombia, y en América Latina comienza a emerger una pléyade intelectual que cuestiona los criterios de validez de la ciencia, los márgenes de legitimación del conocimiento y la necesidad de auscultar la realidad con nuestros propios lentes. Lo que evidenciaba esta pléyade era que "la ansiada "modernización" que hubiera sido promovida por intelectuales y élites estaba dando muestras de imposibilidad" (Vanegas, 2008, p. 14). El propósito de romper las amarras con el pensamiento colonizado/colonizador fue encaminándose propiamente hacia la construcción de un nuevo modo de comprender y hacer una ciencia que supere el cientificismo y se comprometa con las realidades cambiantes de los pueblos, una ciencia guerrillera llegó a proponerse (Varsavsky, 1969/2007), enunciada como "episteme latinoamericana" (Montero, 2008).

Son campeones de este proceso, entre otros, Celso Furtado, Florestán Fernandes, Aníbal Quijano, Pablo González Casanova, Fernando Henrique Cardoso, Teothonio Dos Santos y Paulo Freire (Sánchez, 2008 , p. 10). Como figura emblemática y primera estaba Camilo Torres, el sacerdote y sociólogo colombiano que abandonó el ministerio sacerdotal, sus actividades docentes y sus experiencias de acción y promoción de la comunidad para lanzarse a una acción política abierta y decidida que tuvo en el Movimiento Frente Unido del Pueblo su aportación de mayor riqueza y en su incorporación a las guerrilleras del Ejército de Liberación Nacional (ELN) de Colombia su última estación. Su prematura muerte (15 de febrero de 1966 a los 37 años) junto a la del Che Guevara en 1967, redobló la urgencia de construir marcos científicos y de sentido significativos para la comprensión de la realidad. Durante este período la sociología del compromiso asumió los nombres de sociología de la crisis y sociología de la liberación (Fals Borda, 2013, pp. 149-154; 173 194). La ética del compromiso, que guía esta etapa se caracteriza principalmente por la pregunta "¿investigar para qué?" a la que él mismo responde: "porque hay injusticia, hay explotación... porque el mundo tiene que ser más satisfactorio" y abandona la universidad (Pérez Benavides, 2010, p. 21). 
3. Investigación-Acción (1970 a 2008): A medida que van madurando los debates y las reflexiones se va haciendo más evidente el camino. El proyecto de ciencia que estaba pensando no estaba para desarrollarse en el medio universitario (Fals Borda, 2013, p. 37), que seguía regido por la neutralidad valorativa, con programas académicos desconectados de la realidad de las comunidades y sin mucha perspectiva de utilidad para el cambio de las condiciones de vida que aquellas padecían (Cataño, 2008, p. 87; Cubides, 1995, p. 9), enredado en la rutina académica que limitaba la creatividad científica (Fals Borda, 2013, p. 37; Cubides, 1995, p. 9). Unidos a estos argumentos aparecieron dos motivos más para desencantarse del medio académico: una cada vez más profunda insatisfacción con el sistema político colombiano (enmarcado en el Frente Nacional) y la ineficacia de una izquierda "acartonada, solipsista y dogmática" (Cubides, 1995, p. 9). Por eso renunció a la Universidad y se alejó de ella por veinte años. Es el inicio de esta última etapa que durará hasta el final de sus días.

Parte rumbo a Europa, a Ginebra (Suiza), en calidad de director de investigaciones del Instituto de las Naciones Unidas para el Desarrollo Social, en el mismo período que Paulo Freire está pasando su exilio. (Fals Borda, 2013, p. 37). Allí se encuentra con otros cuatro científicos sociales colombianos y deciden construir una aventura intelectual y política inusitada: una fundación que pusiera en práctica la ciencia que estaban teniendo en mente de manera colectiva, que seguía el esquema de investigar para transformar, en el cual "teoría y práctica debían ser juntas, no separadas [haciendo parte de] un ritmo interpretativo [que se llamó] ritmo reflexión y acción". (Fals Borda, 2013, p.
38) Así nació La Rosca de Investigación y Acción Social a finales de 1969 (Fals Borda, 2013, p. 37; Cataño, 2008, p. 87).

La concepción de ciencia en ellos estaba claramente delimitada. Dicha concepción descartaba la acumulación de datos "como ejercicio epistemológico" que lleva a descubrir leyes de una ciencia pura, porque sí, por la ciencia como fetiche mismo; mucho menos consideraba que su producción estaba destinada a propiciar reformas (a manera de paliativo o parche temporal) que mantuvieran el statu quo. Se buscaba "armar ideológica e intelectualmente a las clases explotadas de la sociedad, para que asuman conscientemente su papel como actores de la historia" (Fals Borda, 2013, pp. 230-231; 245).

El trabajo desarrollado por La Rosca (1970-1976) fue un esfuerzo de construcción del método-perspectiva. Un período de búsqueda, indagación y ensayo y error. Este período demandó cambios significativos evidentes como el público cotidiano y los jueces de los trabajos, pues ya no eran más estudiantes y profesores (grupo de referencia profesional) sino campesinos, sindicalistas y militantes de izquierda (grupos "clave"), lo que "exigía modificar el lenguaje, el estilo y la presentación de los informes de investigación" (Cataño, 2008, p. 88; Fals Borda, 2013, p. 244). No sólo aparecieron los resultados en formato de libro, pues muchos de los integrantes de los grupos clave no sabían leer, sino que emergieron las canciones revolucionarias y populares, las cartillas de historietas, las exposiciones fotográficas y el teatro popular, como formas de socialización de las investigaciones.

La búsqueda de una "ciencia social inspirada en los intereses de las clases trabaja- 
doras y explotadas[,] una nueva ciencia social del pueblo y para el pueblo trabajador" que fuera útil en el "análisis de las luchas de clases (...) así como en la acción política y proyección futura de las clases trabajadoras como actores en la historia" (Fals Borda, 2013, p. 223), implicó una ruptura (que veremos en detalle en el siguiente acápite) frente al paradigma dominante (también Ilamado hegemónico) de la ciencia social, entrañando algunas características que vale la pena mencionar:

1. La necesidad de integrar diversas disciplinas. Había que incluir una visión de conjunto de la sociología, antropología y economía, y vincularlas con conocimientos de la educación popular, bajo un marco referencial filosófico de la historia: el materialismo histórico, porque "en lo social, no puede haber realidad sin historia" (Fals Borda, 2013, p. 223). Este esfuerzo debía centrarse en las realidades, contextos y problemas propios de los de los trópicos y subtrópicos (Fals Borda, 2007).

2. La ratificación sobre el terreno de que la teoría de lucha de clases constituía una constante histórica, lo que exigía de la nueva ciencia "examinar el desarrollo de las luchas de clases del pasado para rescatar de ellas, con fines actuales, aquellos elementos que hubieran sido útiles para la clase trabajadora en sus confrontaciones con la clase dominante" (Fals Borda, 2013, p. 227).

3. La comprensión de que vincular teoría y acción, conocimiento y práctica, entrañaba "un esfuerzo permanente e inacabado de comprensión, revisión y superación sobre una cuesta sin fin, difícil y llena de tropiezos" como en el castigo de Sísifo (Fals Borda, 2013, p. 215).

4. La constatación de que "el investigador consecuente puede ser al mismo tiempo sujeto y objeto de su propia investigación y experimentar el efecto de sus trabajos [lo que lo debía obligar a comprender que existía] una secuencia de ritmos en el tiempo y el espacio que incluyen acercarse y distanciarse de las bases, acción y reflexión por turnos" (Fals Borda, 2013, p. 219; Cataño, 2008: p.88). Este proceso promueve la transformación de la personalidad/cultura del investigador enfatizando su vivencia personal y compromiso moral e ideológico con las luchas por el cambio radical de las sociedades (Fals Borda, 2007).

5. El entendimiento de que la investigación social y la acción política "pueden sintetizarse e influirse mutuamente para aumentar tanto el nivel de eficacia de la acción como el entendimiento de la realidad". (Fals Borda, 2013, p. 224-225)

6. Con inspiración en Gramsci se llegó a la urgencia de romper el monopolio del conocimiento (Fals Borda, 2013, pp. 253-263) que implicaba superar la visión elitizada del saber, atribuida casi en forma exclusiva al mundo científi- 
co, para "tomar en cuenta el saber [popular] y la opinión experimentada de los cuadros y de otras personas informadas de las regiones y localidades" (Fals Borda, 2013, p. 230). Este diálogo de saberes (también llamado como suma de saberes) entraña un proceso de devolución sistemática del conocimiento adquirido y construido colectivamente de manera inteligible (Fals Borda, 2007).

La experiencia de La Rosca generó varias publicaciones bajo esta perspectiva y promovió un Congreso Mundial de esta tendencia en 1977. El compromiso científico-militante llevó a Orlando Fals por los caminos de la articulación con experiencias periodísticas como la fundación de la Revista Alternativa (1974-1980) junto a Gabriel García Márquez, los mejores periodistas del país y algunos intelectuales. En esta revista Fals Borda publicó una columna llamada "Historia prohibida". Estos procesos lo pusieron en el ojo de la represión y la padeció en carne propia, primero al ser puesto preso -junto a su esposa-, acusados de una militancia en la socialdemócrata guerrilla del M-19, y posteriormente a un breve período de exilio que le permitió hacerse partícipe de la experiencia de la Revolución Sandinista en Nicaragua, donde se reencuentra con Freire.

La década de 1980 fue rica en experiencias, reflexiones e intercambios con América Latina. Los temas de sus libros durante esta década giraron en torno a la relación entre conocimiento y poder popular (Fals Borda, 1986), la formalización y organización de su propuesta: la Investigación-Acción Participativa (IAP), una pers- pectiva, para su asombro, en vías de normalización (Cataño, 2008, p. 90), el ordenamiento territorial (Fals Borda, 1988) y la monumental Historia Doble de la Costa, escrita en cuatro tomos (entre 1979 y 1986). También escribió artículos sobre el socialismo, la democracia y los movimientos sociales.

La década de los noventa lo encontró reflexionando y profundizando, principalmente sobre el ordenamiento territorial, y en sus últimos años (2000-2008) esforzándose por repotenciar la dimensión política de la ciencia, organizando reediciones de libros $u$ organizando unos nuevos en perspectiva de potencia política para la coyuntura de entonces y las generaciones por venir. Vale anotar, finalmente, que la ética de este período (ética cristiana ecuménica) puede entenderse "como un activismo profético, en cuanto incluye denuncia, esperanza y práctica consecuente" (Castillo-Cárdenas, 2010, p. 21).

\section{Las rupturas con el paradigma domi- nante}

En el desarrollo del pensamiento-acción de Orlando Fals Borda se va generando un proceso progresivo, consciente y decidido de ruptura epistemológica con los modelos europeos y norteamericanos de ciencia social, importados acríticamente e implantados irreflexivamente en las academias latinoamericanas. Esta discusión y ruptura lo llevan a plantearse la necesidad de construir un nuevo paradigma endogenético.

La diferencia con estos modelos (racionalismo cartesiano sumado al positivismo, mecanicismo newtoniano, materialismo dogmático y funcionalismo parsoniano) 
(Fals Borda, 2013, pp. 82-83) entrañaba no sólo una confrontación epistémica (en relación con los marcos de referencia y las categorías, a veces inaplicables a la realidad existente por su supraparcelación y ultraespecialidad) sino también política para Orlando, pues los denunciaba como las columnas que sostenían, justificaban e impulsaban las políticas equivocadas del capitalismo. Por eso, dijo en alguna ocasión, que era "inconsistente en científicos sociales y naturales, y en profesores, académicos y estudiantes que sigamos ajustando nuestros juicios y valores y los pénsumes de nuestras escuelas, a aquellos moldes obsoletos y perjudiciales en tantos sentidos". (Fals Borda, 2013, p. 88; 215) Veamos un poco las cuatro rupturas que adelanta Orlando Fals Borda.

1. Ruptura con el positivismo. Como todos sabemos, para el enfoque positivista sólo existe una realidad, que es objetiva e independiente del sujeto cognoscente, ya que el sujeto es subjetivo (porque tiene creencias, prejuicios, sentimientos, apuestas políticas, decisiones éticas, etc.) y su subjetividad incide negativamente en la búsqueda de objetividad en el conocimiento. Este enfoque "condena a muerte la subjetividad, por considerarla metafísica y tóxica para la consecución de un conocimiento científico objetivo". Por tal motivo, "no hay diferentes tipos de conocimientos [...] hay sólo un conocimiento de importancia, el de la ciencia positiva" (Crecer, 2010: pp. 144, 146).

Desde este enfoque, la ciencia es considerada como mero reflejo directo de la realidad al cual se accede, mediante la metodología y las técnicas observacionales propias del experimento, llegando inclusive a reducir el problema de la ver- dad científica a la correspondencia entre enunciados y realidad. De este enfoque se construye la ya histórica tradición de concebir la producción del conocimiento con asepsia científica (Martín-Baró, 1986), o neutralidad valorativa (Fals Borda, 2013), a fin de alcanzar el estatus de ciencia.

Dazinger (2000-2001, p. 3) advierte tres características de la ciencia positivista: 1) la noción de "progreso acumulativo del conocimiento" que será medido por el número de publicaciones de investigación; 2) las categorías explicativas son profundamente ahistóricas y acontextuales por su anhelo de universalidad; $y, 3)$ La rigidez de las normas que orientan la actividad científica, las cuales siempre han sido las mismas y han existido como ideas.

La ruptura de Orlando Fals Borda con el positivismo está cifrado en tres aspectos. El primero de ellos es la ruptura de la relación de sumisión, opresión y dependencia entre quien investiga $y$ quien es investigado (relación sujetoobjeto) en el sentido de que no es simplemente el "Sujeto" el que investiga, sino que también el "Objeto" participa del proceso; es decir, que el "Objeto" no es un ente pasivo de conocimiento, sino un "Sujeto" activo cognoscente. Por ello, asume la dialogicidad como forma privilegiada de intervenir y de construir, que entraña una relación de horizontalidad e interimplicancia; el segundo de ellos es la ruptura de la pretensión de objetividad, vinculado a sus deseos de imparcialidad. El saber construido desde esta perspectiva se convierte en un saberpoder, síntesis dialéctica del saber científico y el saber popular, llamado "Saber Revolucionario". (Fals Borda, 1986); el tercer elemento lo constituye la necesaria histo- 
ricidad de las circunstancias sociales ("realidad").

Esta ruptura, que entraña no sólo una posición política sino un sentido ético, permiten construir colectivamente el saber y armar las técnicas y las herramientas necesarias para la tarea.

2. Ruptura coneleurocentrismo. La ciencia social dominante, venida de los centros de poder europeo y norteamericano, ha pretendido constituirse en un discurso de universalidad y totalidad, aplicable y replicable en todas las condiciones socioculturales del planeta, como un modelo único, válido y posible de hacer ciencia, en general, y ciencia social, en particular. Esta tradición etnocéntrica ha pretendido identificar a Europa, primero, y luego a Estados Unidos, con la "UniversalidadMundialidad", al autodenominarse centro del mundo, herencia del pensamiento hegeliano. (Dussel, 2005, p. 48) Es lo que el economista egipcio Samir Amín enunció como eurocentrismo, el "elemento culturalista del capitalismo moderno en expansión" (Fals Borda, 2003).

El eurocentrismo se erige, desde el Renacimiento, sobre una fusión novedosa de lo occidental latino con lo griego oriental que da como resultado la siguiente ecuación: Occidente $=$ Helenístico + Romano + Cristiano (a la que luego se le agrega el romanticismo alemán). (Dussel, 2005, p. 43-44) Orlando Fals Borda la define como "Ia secuencia clásica del Mar Mediterráneo: Egipto-Grecia-Roma-Judea" (Fals Borda, 2013, p. 89).

Orlando Fals Borda va a anteponer al eurocentrismo una novedosa forma de hacer ciencia -que no es otra cosa distinta que retomar experiencias anteriores marginalizadas del mundo pensante latinoamericano- que va a denominar como ciencia propia, "vernácula", "raizal". Este modelo científico debe hurgar en las raíces del pensamiento propio y construir un conocimiento vivencial (Fals Borda, 2013, p. 155-163) vinculado al entorno vital propio de los ecosistemas del trópico y el subtrópico que condicionan las formas de pensar, sentir y actuar de nuestros grupos culturales y étnicos (Fals Borda,

2013, pp. 82; 98). Parte del convencimiento de que los marcos de referencia científicos son obras humanas que "se inspiran y fundamentan en contextos geográficos, culturales e históricos concretos". (Fals Borda, 2013, p. 94) La superación del colonialismo intelectual (expresión acabada de eurocentrismo) estará cifrada en la construcción de una cienciasaber sistémico, endogenético y raizal que nos impulse, guíe y anime en la aventura de conocernos a nosotros mismos como pueblos, culturas, historias y sociedades. Dice el propio Orlando

Tenemos que aprender a hablar huitoto, chibcha, quechua, y no sólo en castellano, inglés o francés. Porque nuestra tradición es más compleja y amplia que la de los europeos, como lo es también la fauna, flora y alimentos en comparación con los de las zonas templadas de la tierra. Aquí el sol es más radiante y en los Andes tenemos las cuatro estaciones en un solo día. Por eso, a aquella secuencia formativa del Mediterráneo que nos han inculcado desde la cuna, debemos añadir nuestro propio panteón anfibio con las maravillas explicativas de los grupos humanos que ocuparon e hicieron producir antes que nadie todas estas tierras, empleando para ello una cadena formativa muy diferente: la Maya-Arawak- 
Chibcha-Inca-Guaraní, la de la "América Profunda", que es tanto o más rica que la otra secuencia (Fals Borda, 2013, p. 90).

Este esfuerzo falsbordiano podría advertirse como una anticipación de una epistemología del sur (Sousa, 2009) libre de las amarras colonialistas de derechas y de izquierdas.

3. Ruptura con el racionalismo. La supremacía de la razón lógico-matemática de fundamento Kantiano y Cartesiano se ha erigido, en no pocas ocasiones, como el valor supremo y fin último del sino humano. Prueba de ello están las evidencias de su capacidad destructora y despersonalizante en hechos como los de la Alemania Nazi descritos por Ana Arendt. El racionalismo, la racionalidad, está en el basamento del modelo de producción y de reproducción de la muerte (no hay reproducción de la vida) propios del capitalismo y tienen muchísima relación, sin duda, con el constructo del hombre unidimensional denunciado por Herbert Marcuse en el año de 1964.

Orlando Fals Borda, en el segundo tomo de la Historia Doble de la Costa titulado "Resistencia en el San Jorge" hablará del Hombre-Icotea, una imagen popular que significa el sentido de la resistencia y supervivencia de aquellas gentes: los hombres-anfibios que logran construir una vida en las tierras cenagosas e inundables. Esta alegoría anfibia, tan propia de la cultura caribe colombiana, la toma prestada el maestro para llevar a constructo teórico, a categoría conceptual. Lo que en los pescadores del río San Jorge será enunciado como "hombre-icotea" en Fals Borda será desarrollado como "sentipensan- te". Y es precisamente el sentipensamiento la ruptura con el racionalismo europeo.

El sentipensamiento puede definirse como una síntesis dialéctica entre el pensar y el sentir: el pensar-sintiendo y el sentirpensando; "un acto de "combinar la mente con el corazón", la razón con el sentimiento, estrategia del saber empático que recuerda los mecanismos diltheyanos de vivencia (vida experimentada) y de comprensión (reconstrucción y vivificación imaginaria de una experiencia ajena para conocerla mejor)" (Cataño, 2008, p. 88-89). Un hombre, o mujer sentipensante es aquella persona que no escinde lo que piensa de lo que siente, lo que anhela de lo que hace, lo que escribe de lo que sueña, que combina la reflexión con la acción (praxis emancipatoria), que hace ciencia con pasión, amor y angustia (categorías válidas y urgentes en Fals Borda). Por eso el sentipensante es necesariamente revolucionario y enamorado de la vida.

El planteamiento del "corazonar" planteado desde la antropología por el ecuatoriano Patricio Guerrero Arias (2010; 2011) y entendido como una dimensión fundamental en la relación ciencia-política que apunta hacia la descolonización del poder, del saber y del ser, se hermana, indudablemente, con la proposición falsbordiana del "sentipensamiento".

4. Rupturaconelfuncionalismo. El modelo de interpretación de las realidades sociales propuesto por el norteamericano Talcott Parsons abogaba por la comprensión de las sociedades como "sistemas sociales" con un "orden social" preestablecido que debía describirse y sostenerse. En dichos sistemas era necesario detectar los roles que cada ciudadano cumplía para mantener la buena funcionalidad de 
la estructura. Este modelo homeostático consideraba que categorías y realidades sociales tales como "el conflicto", la "subversión", el "cambio social" o la violencia no eran otra cosa que síntomas de anormalidad que debían ser relegadas a la marginalidad científica y estudiadas como "desviaciones" del modelo social. Era un modelo tendiente "a la integración y al equilibrio social" (Fals Borda, 2013, p. 224) que lo hacían paradigma del sostenimiento del statu quo.

Como se ha dicho, Orlando Fals Borda construye un modelo científico basado en las premisas de marginalidad propuestas por el enfoque parsoniano. Ubica en el centro del debate científico el cambio social (necesario), estudia la subversión, la antiélite, la violencia y el conflicto. De a poco va estructurando una ciencia novedosa, rebelde y subversiva, descolonizadora y vernácula, que aproxima explicaciones referidas a las sociedades latinoamericanas (en crisis) e intenta desnudar el modelo inequitativo e inicuo que se ha naturalizado y referido como la norma para la producción y reproducción de la vida. Orlando Fals Borda establecerá un agudo análisis que deja al descubierto que en nuestros países no existe un Orden Social sino un "desorden ordenado" y por lo tanto es requisito sine qua non de la ciencia y de sus cultores, los científicos, abogar por el cambio de estructuras, esto es, en la línea de lo que venimos hablando, "poner en orden el desorden".

Las rupturas con el modelo hegemónicotradicional de hacer ciencia, que hemos mencionado, permiten ubicar a Orlando Fals Borda en la pléyade de intelectuales latinoamericanos y latinoamericanas que fueron construyendo nuestra propia episteme (Montero, 2008, p. 27-28) caracteri- zada por varios elementos de los cuales queremos llamar la atención sobre tres de ellos, que consideramos los ejes: enfoque, metodología y horizonte. En la episteme latinoamericana el enfoque es el descolonizador heterodoxo, en el sentido de que busca las raíces del pensamiento propio (sin xenofobias) y no tiene problema en beber de los saberes, constructos y experiencias diversas para construir su modelo, rompiendo la tradicional mitosis científica de disciplinas y subdisciplinas, en algunas ocasiones insulsas y desconectadas del mundo de las sociedades. La metodología no puede ser otra que la praxis, entendida como la síntesis dialéctica de teoría y práctica, en espiral ascendente, con perspectiva de cambio radical. Y el horizonte común de nuestra episteme es, sin lugar a dudas, la liberación científica, cultural, política, económica, religiosa y simbólica. Por supuesto que estos tres elementos (enfoque, metodología y horizonte) están supeditados de manera insoslayable al reconocimiento del Otro como sujeto fundamental de la construcción de la ciencia y de la vida. Esto es la ética de la otredad como principio.

\section{La educación superior en clave falsbor- diana}

Nos parece importante que dediquemos algunas líneas para examinar cuáles serían los postulados que Orlando Fals Borda tendría para la educación superior, tomando en cuenta sus raíces, recorrido científico y rupturas epistemológicas. $\mathrm{Si}$ hemos hecho todo este recorrido es porque considerábamos de primera necesidad aportar algunos elementos de comprensión básicos para entender las propuestas que aquí expondremos.

Ciertamente Orlando Fals Borda no tuvo 
como centro o eje de su reflexiónacción al tema de la educación superior; sin embargo, y a pesar de haber estado alejado veinte años de la academia, y haber construido su propuesta en los márgenes de la estructura universitaria, consideramos que el tema educativo nunca estuvo apartado de su análisis y que desde su lugar de educador de campesinos (como lo llamó alguna vez el doctor Napoleón Saltos en un intercambio) plantea algunas urgencias para pensar la educación superior. Así pues, proponemos para la reflexión las siguientes tareas que nos deja Fals Borda para el mundo académico-formal:

\section{La promoción de la subversión y las} anti-élites. Lejos de ver la subversión como una categoría negativa para la sociedad, y de advertir en los subversores o rebeldes condiciones de inhumanidad, enemistad o resentimiento, Orlando Fals Borda la describe como una acción con funciones positivas para las sociedades, "como una estrategia mayor y un proceso de cambio social y económico visto en toda su amplitud", en la cual se reflejan todas las incongruencias que entraña un orden social concreto "descubiertas por miembros de este en un período histórico determinado, a la luz de nuevas metas ("utopía") que una sociedad quiere alcanzar" (Fals Borda, 2013, p. 51). La naturaleza de la subversión no puede juzgarse como moral o inmoral porque "no proviene sólo de la dinámica histórica del pasado, sino de la proyección utópica que tiene la acción subversiva hacia el futuro". (Fals Borda, 2013, p. 50).

En Fals Borda, el subversivo posee una actitud positiva hacia la sociedad que le impide ser presa del resentimiento ya que este sentimiento "es una intoxicación de uno mismo (...) que no proyecta una imagen futurista. Lejos de consumirse como un resentido, el subversor se sacrifica por el grupo y se torna en un gran altruista", actitud que lo lleva a convertirse en "la conciencia de una colectividad que despierta y que lleva a todos a una inusitada aventura existencial" (Fals Borda, 2013, p. 49). Los subversores "no pretenden "destruir la sociedad" porque sí, como un acto ciego y soberbio (...) sino lo que consideran incongruente con sus ideales, y tratan más bien de reconstruir la sociedad según nuevas normas y pautas" (Fals Borda, 2013, p. 49; 58).

Ahora bien, existe un grupo social que puede ser determinante en el impulso de la subversión: la anti- élite. Este grupo social podría ser definido como el disórgano de la élite, el cual monopolizando el prestigio y el poder de una sociedad, condición inherente de su grupo (élite), decide retar a sus pares "con el propósito de variar las reglas del juego y la estructura de poder de la sociedad (especialmente en sus estratos más altos)" (Fals Borda, 2013, p. 110); dicho en otras palabras, una anti-élite es "aquel grupo de personas que ocupando posiciones de alto prestigio se enfrentan a los grupos dominantes para arrebatarles el poder politico" (Fals Borda, 2013, p. 110).

Son "posiciones de alto prestigio" aquellas que se logran al alcanzar símbolos valorados "especialmente en relación con el conocimiento y la educación, el poder político y eclesiástico, la riqueza, y las actividades administrativas o de explotación económica (...) aunque no pertenezcan a las clases altas o aristocráticas"; es más, puede aseverarse que se forman "por grupos claves de jóvenes de clase media y alta que, al advertir fallas de 
conducción política en las oligarquías de sus mayores y faltas de orientación ética en instituciones formativas, se rebelan contra sus mayores y proclaman la doctrina de la rebelión justa", inspirados en santos o en seglares anarquistas o de otras tendencias revolucionarias. (Fals Borda, 2013, p. 110; 120)

La anti-élite puede ser generacional o ideológica. La del segundo tipo cumple tres funciones principales para el cambio social: (a) Iniciar la creación y difusión de antivalores y antinormas dentro del orden social establecido; (b) servir como grupo de referencia a otras colectividades rebeldes ubicadas en los, diferentes niveles o estratos de la sociedad; y, (c) retar a los grupos dominantes desde adentro, utilizando sus propias armas y procedimientos (Fals Borda, 2013, p. 111).

La educación superior debe propender a promover simultáneamente la búsqueda de nuevas metas (utopías) y la destrucción de viejos paradigmas anquilosados que retrasan o impiden los procesos de cambio social o radicalidad de experiencias alternativas. La perspectiva debe estar encaminada a la potenciación dentro del estudiantado de verdaderos nichos rebeldes, las cuales, vinculadas a grupos de referencia como los movimientos sociales, promuevan grupos de estudio y aproximación de autores y debates rebeldes animando la constitución de nuevas antiélites científicas.

\section{La implementación de un modelo dia-} léctico de la extensión. En Orlando Fals Borda se advierte una necesidad inaplazable de "derribar los muros que aún separan, más de la cuenta, a la universidad de la comunidad". (Fals Borda, 2013, p. 144) Para ello, la universidad debe sufrir un fenómenos de deselitización, que pueden ser impulsados por la conformación de nichos de anti-élites a la manera de minorías activas (Moscovici, 1996). Este proceso puede ayudar a ampliar la perspectiva universitaria a contextos comunitarios "cuyos problemas y cuestionamientos se incorporarán a la educación superior" (Fals Borda, 2013, p. 78). Así pues las tesis e investigaciones (aún en el pregrado) podrían ayudar a reflejar la preocupación por la justicia de las mayorías populares (Fals Borda, 2013, p. 78), entendiendo que la tarea de extensión, como acción universitaria, debe ir vinculada fuertemente a los procesos de investigación y docencia.

Es necesario añadir que en Orlando Fals Borda la noción de extensión no sólo está pensada en "poner a funcionar el modeIo", esto es, garantizar que la universidad pueda intervenir en las comunidades para ayudarlas a mejorar sus condiciones de vida; también está pensada en términos de una ruptura de este modelo clásico. ¡No basta con que la universidad "vaya a la comunidad"! También es urgente, muy urgente, que la comunidad "entre a la universidad" a través del establecimiento de una extensión al revés (Sousa, 2013) a fin de que se constituya la universidad polifónica.

Una extensión al derecho puede permitir que estudiantes y profesores compartan períodos con las comunidades y los grupos de referencia, compartiendo la vida y la cotidianidad, y puedan retornar luego a la universidad a discutir lo que vivieron, lo que vieron, lo que sintieron y busquen en las teorías los insumos que complementen el panorama. Entonces, este tipo de extensión sería la puesta en práctica en el ámbito universitario del ritmo de refle- 
xión-acción por el que apuesta la Investigación-Acción Participativa (IAP). ${ }^{1}$ Este proceso quizás pueda ayudarnos en varias direcciones: la primera, es que puede servir como vacuna para la arrogancia intelectual, con su actitud de diferenciación del trabajo intelectual y el trabajo manual; la segunda, que tal vez ayude a "encontrar" temas de investigación en los y las jóvenes para resolver la angustia de hacer una investigación para recibir sus títulos (aún en el pregrado), pues el contacto con la realidad puede servir de estímulo y abono para encontrarlos; y, la tercera, que este encuentro permanente con la realidad promueva que los temas de indagación estén más próximos a la realidad social y no sólo salgan de la imaginación personal e individual del estudiante, entonces podremos construir una ciencia ligada a la realidad "real" y alejada de la realidad "científica", de esos temas que se construyen y se autorreproducen en cadenas de citas bibliográficas o cogitaciones de escritorio con pretensión de terreno. ${ }^{2}$

Por su parte, una extensión al revés puede ayudar, al desarrollo de una educación humanista, superior a la que se ha logrado hasta ahora, que además de cultivar la Razón pueda incorporar y reconocer las "capacidades intuitivas, extra-académicas

\footnotetext{
${ }^{1}$ En Brasil se están dando experiencias muy significativas entre intelectuales universitarios y el Movimiento Sin Tierra, MST, que vale la pena explorar. En Colombia se ha venido impulsando, de a poco, algunas experiencias también

${ }^{2}$ Queda implícita la vinculación entre la perspectiva de Orlando Fals Borda con la de Camilo Torres Restrepo, en el sentido de luchar frontalmente contra el "paternalismo práctico", reconociendo el papel central del pueblo y sus conocimientos; también habría que destacar la reivindicación que Fals hará de Wright Mills en el sentido de oponerse a la conformación de los científicos como un "ejército de expertos".
}

y hasta esotéricas (...) que provienen de vivencias y experiencias (...) originadas en la historia de los pueblos y el sentido común". Porque como dice el propio Fals Borda "iCómo sería de agradable trabajar en una institución que permita estas expresiones, donde no se privilegien las ciencias Ilamadas "duras", la objetividad autorreferenciada y mensurable, aunque sin desconocerlo en lo necesario!" (Fals Borda, 2013, p. 78), Que la universidad se arriesgue a incorporar en su desarrollo académico modalidades de "cátedras libres" coordinadas, impulsadas o promovidas desde las necesidades de los grupos de referencia, las comunidades y las minorías activas. La extensión al revés va en la dirección de lo planteado por el Che Guevara:

"Y, ¿qué tengo que decirle a la Universidad como artículo primero, como función esencial de su vida en esta Cuba nueva? Le tengo que decir que se pinte de negro, que se pinte de mulato, no sólo entre los alumnos, sino también entre los profesores; que se pinte de obrero y de campesino, que se pinte de pueblo, porque la Universidad no es el patrimonio de nadie y pertenece al pueblo de Cuba, (...) y el pueblo que ha triunfado, que está hasta malcriado en el triunfo, que conoce su fuerza y se sabe arrollador, está hoy a las puertas de la Universidad, y la Universidad debe ser flexible, pintarse de negro, de mulato, de obrero, de campesino, o quedarse sin puertas, y el pueblo la romperá y él pintará la Universidad con los colores que le parezca" (Guevara, 1959). 
3. La urgencia de romper el monopolio del conocimiento. Es necesario incorporar a la dinámica propia de la vida universitaria el reconocimiento del Otro, representado en los estudiantes y en las comunidades y grupos de referencia. Es la conciencia ética de la existencia de los demás, no como simples estadísticas o depositarios de un saber (al modelo bancario denunciado por Freire).

Mostrar esta disposición académica, de aproximación en la cátedra, en la búsqueda de la teoría, debe permitir que la universidad se abandere de la construcción de una verdadera ecología de saberes (Sousa, 2009, pp. 160-209). Es la síntesis del saber popular y el saber científico que debe apostar por la construcción de un saber-poder revolucionario que ayude a la universidad a superar las taras de neutralidad valorativa y servilismo científico mimetizado en la máscara de la objetividad.

Romper el monopolio del conocimiento representa el reconocimiento de la diferencia y de la pluralidad; que sabe que el conocimiento científico occidental es sólo uno de los muchos posibles y que puede, necesita, idebe!, pasar las voz a las comunidades, los grupos de referencia, para que ellas y ellos participen activamente en la construcción de conocimiento válido y útil para sus procesos. Este saber-poder producto de la polifonía del conocimiento debe vincular los debates y las disputas sobre la memoria social y la historia oral, la ciencia social militante y raizal que anime y potencia la lucha popular y las necesidades comunales.

4. Ladefinitiva emancipaciónintelectual. Es necesario avanzar en la irrenunciable misión histórica de la universidad de investi- gar la realidad en profundidad. Conocer la realidad y conocerla bien es el prerrequisito para la transformación de un modelo de sociedad o la profundización de un anhelo histórico sobre la base de avances que hayan ocurrido en nuestros pueblos. Una universidad que no investiga es una tecnología de la dominación. En este proceso, la investigación ha de estar en el centro de la tarea universitaria. Porque si la universidad no investiga, la criba crítica desaparece; lo que hace más proclive a una sociedad a ser presa de la enajenación, la explotación capitalista, los retrocesos históricos y las conversiones políticas.

La universidad debe considerar a la investigación (diferente de información) como su herramienta pedagógica de mayor valor, pues en ella debe sustentar su autonomía académica. Esta tarea debe tener como prioridad "la consolidación de un ambiente cultural que propicie la creatividad a lo largo de todas las etapas de formación que contribuyan al proceso de reconstrucción social y al bienestar de las mayorías desprotegidas de la población". (Fals Borda, 2013, p. 101)

La emancipación intelectual demanda recuperar las actitudes que revitalizó Wright Mills: "su inspiración de la tradición de la sociología dinámica, la sensibilidad política y el celo misionero por el cambio social" (Fals Borda, 2013, p. 104) y su invitación constante a la revitalización de la creatividad y la imaginación (Wright Mills, 2003, p. 206-236), invitaciones también hechas por Mariátegui y Simón Rodríguez. La labor creativa privilegiará la incursión en nuevos temas ligados a nuestros pueblos, de incidencia real para ellos, y no sólo consistirá en la bulimia intelectual de ratificar o validar lo ya descubier- 
to, esclarecido o abierto. En este sentido, si las categorías no existen tendremos que crearlas.

Esta tarea significa la construcción de la ciencia vernácula, endógena y raizal que supera la instrumentalización servil del conocimiento para la acumulación capitalista y que valida los conocimientos que produce "principalmente por su originalidad, pertinencia y utilidad para nuestra sociedad". (Fals Borda, 2013, p. 100). Los indicadores de validez y de excelencia deben relacionarse más con "la forma como analizamos y acumulamos el conocimiento derivado de estos semidesconocidos mundos [del trópico]" (Fals Borda, 2013, p. 78) que con la publicación de resultados en revistas científicas del primer mundo bajo los parámetros y cánones impuestos por aquel. Seguir los moldes establecidos significa continuar reproduciendo los modelos de explotación y dominación tanto en la actividad científica como en la vida cotidiana.

\section{La necesaria construcción de modelos} abiertos, flexibles, trans e interdisciplinarios. Es urgente que la universidad comience a pensar sus propias estructuras (departamentos, escuelas, facultades) en términos de los problemas de las sociedades y no como nichos científicos o parcelas epistemológicas pensadas más en la reproducción del conocimiento que en la realidad social. La mitosis propia del medio universitario en no pocas ocasiones es el resultado de arrogancias o mezquindades internas, o bien de angustias personales bienintencionadas, desarticuladas de un esfuerzo de comprensión abarcadora de los problemas cotidianos que ocurren en los extramuros de las instituciones.
Al mismo tiempo, Fals Borda nos invita a incorporar modelos flexibles y abiertos que incluyan como parte de la formación de base las angustias y proposiciones de las comunidades y los grupos de referencia, así como las búsquedas y deseos de los estudiantes, por medio de la apertura de cátedras libres y de movilidad universitaria. La inclusión en la cotidianidad académica de las reflexiones en torno a una comprensión del mundo desde el pensamiento complejo propuesto por Morin.

\section{Comentarios finales}

Es cierto que los tiempos han cambiado desde los planteamientos de Fals Borda a estos que nos están tocando vivir. Encaramos un nuevo período de colonialismo (neocolonialismo) con un universo científico inconmovible. Los núcleos opositores y contrahegemónicos siguen luchando, aunque dispersos. Las universidades y el conocimiento científico están convirtiéndose cada vez más en instrumentos de legitimación, acercándose a la noción de tecnología que de producción del saber. La ciencia se erige en un fetiche autorreferenciado. Es un momento difícil el que estamos viviendo.

Sin embargo, las angustias de los pueblos siguen a la orden del día y las lacerantes realidades están demandando una actitud creativa. Orlando Fals Borda era bastante pesimista respecto de la institucionalización de la IAP pero nunca dejó de creer en la lucha necesaria por cambiar la correlación de fuerzas al interior de la institución educativa. Erich Hobsbawm ya nos había advertido que los procesos de cambio no los hacen los intelectuales, pero 
también es cierto que no se puede hacer sin o contra ellos.

Las aportaciones de Fals Borda al medio universitario pueden ayudar en la tarea emprendida por grupos dinámicos al interior de las instituciones que siguen creyendo que la academia debe transformarse para beneficio de las mayorías y en el camino del mejoramiento de las condiciones de vida de la humanidad. Lo dicho por Orlando, un iconoclasta del medio universitario, no es un camisa de fuerza, simplemente siguen siendo insumos para tener en cuenta en los propósitos más nobles que nos animen.

Espero que estas líneas ayuden en la tarea trazada por los estudiantesprofetas de la Reforma de Córdoba para la superación del anacronismo y dogmatismo que han alejado a grandes sectores de la academia de la vida de las gentes humildes y que los siguen manteniendo en la rutina y la repetición. Que ojalá podamos repetir con aquellos héroes culturales y libertarios: "Recojamos la lección, compañeros de toda América; acaso tenga el sentido de un presagio glorioso, la virtud de un llamamiento a la lucha suprema por la libertad" (Federación, 1918).

\section{BIBLIOGRAFÍA}

BERGER, Peter \& LUCKMANN, Thomas (1979). La construcción social de la realidad. Buenos Aires, Argentina, Amorrortu.

CARRETA (2011). "Orlando Fals Borda: perfil biográfico".

Recurso electrónico disponible en: http://losejesdemicarreta.blogspot.com. ar/2011/05/orlando-fals-borda-perfilbiografico.html.Consultado el 31 de octubre de 2013.

CASTILLO-CÁRDENAS, Gonzalo (2010). "La influencia religiosa en la ética social de Orlando Fals Borda", en PÉREZ BENA VIDES, Isay (2010) La influencia religiosa en la conciencia social de Orlando Fals Borda. Barranquilla, Colombia, Corporación Universitaria Reformada, pp. 15-23.

CATAÑO, Gonzalo (2008). "Orlando Fals Borda, sociólogo del compromiso", en Revista de economía institucional, Vol. 10, No. 19, segundo semestre de 2008, pp. 79-98. Recurso electrónico disponible en: http://www.economiainstitucional.com/ pdf/No19/gcatano19.pdf. Consultado el 30 de octubre de 2013.

CRECER (2010). Razones epistemológicas, sociales y político-administrativas para pensar la psicología en una Facultad de Ciencias Sociales y Humanas. En Crecer (2010), Vulnerabilidad y derechos de la niñez (pp. 139-170). Neiva, Huila, Colombia, Universidad Surcolombiana-Programa de Psicología-Grupo de Investigación CRECER.

CUBIDES C., Humberto J. (1995). “Orlando Fals Borda: el permanente compromiso de un innovador", en Revista 
Nómadas, No. 2, marzo de 1995. Bogotá, Colombia: Universidad Central.

Recurso electrónico disponible en: http://www.redalyc.org/articulo.oa?id=1 05115242011. Consultado el 1 de noviembre de 2013.

DANZINGER, K. (2000-2001). Los orígenes sociales de la psicología moderna. Editado por www.elseminario.com.ar

DUSSEL, Enrique (2005). "Europa, modernidad y eurocentrismo", en LANDER, Edgardo (Comp.) (2005) La colonialidad del saber: eurocentrismo y ciencias sociales. Perspectivas latinoamericanas. Buenos Aires, Argentina: Clacso, pp. 41-53.

FALS BORDA, Orlando (1981). Ciencia propia y colonialismo intelectual. Bogotá, Colombia: Carlos Valencia Editores.

(1967/2008). La subversión en Colombia. El cambio social en la historia. Cuarta edición. Bogotá, Colombia, FICA-CEPA.

-(1986a) Conocimiento $y$

poder popular. Lecciones con campesinos de Nicaragua, México, Colombia. Bogotá, Colombia: Siglo XXI editores.

1988) La insurgencia de las provincias. Hacia un nuevo ordenamiento territorial para Colombia. Bogotá, Colombia: Universidad Nacional - Siglo XXI editores. [En coautoría con Ernesto Guhl Nimtz]

(2003) Ante la crisis

del país: ideas-acción para el cambio. Bogotá, Colombia, El áncora editores.

-(2007). Superación del eurocentrismo científico como base para un desarrollo endógeno suramericano. Conferencia en el simposio sobre desarrollo endógeno, biodiversidad y cultura. en HAVERKORT, Bertus; RIST, Stephan (edit.). (2007): Endogenous development and bio-cultural Diversity: the interplay between worldviews, globalization and locality. COMPAS/CDE (pp. 130-136). (Tomado de Internet: Capturado 26 de mayo de 2010 de: www.compasnet.org/afbeeldingen/Books ¿EDBCD/Borda.pdf).

--(2013).Ciencia, compromiso

y cambio social. Antología. HERRERA FARFÁN, Nicolás Armando y LÓPEZ GUZMÁN, Lorena (Comps.) Buenos Aires, Argentina: editorial El Colectivo, editorial Lanzas y Letras, Extensión Libros.

FEDERACIÓN Universitaria de Córdoba. (1918). Manifiesto de la Federación Universitaria de Córdoba. Recurso electrónico disponible en: http://www.reformadel18.unc.edu.ar/ma nifiesto.htm. Consultado el 29 de octubre de 2013.

FERNÁNDEZ RETAMAR, Roberto (2006). Todo Caliban. La Habana, Cuba: Fondo Cultural del Alba. GUERRERO ARIAS, Patricio. (2010) Corazonar. Una antropología comprometida con la vida. Quito-Ecuador, Abya Yala - Universidad Politécnica Salesiana.

-(2011) “Corazonar la dimensión política de la espiritualidad y la dimensión espiritual de la política", en Alteridad. Revista de Ciencias Humanas, Sociales y Educación, No 10, 2011, p.21-39. Quito, Ecuador, Universidad Politécnica Salesiana. 
GUEVARA, Ernesto. (1959) Discurso al recibir el doctorado honoris causa de la Universidad Central de las Villas, el 28 de diciembre de 1959. Recurso electrónico disponible en: http://www.marxists.org/espanol/guevar a/59-honor.htm. Consultado el 29 de octubre de 2013.

MARTÍN-BARÓ, Ignacio (1986). "Hacia una psicología de la liberación", en Boletín de psicología No. 22, pp. 219-231. San Salvador, El Salvador, UCA Editores.

MONTERO, Maritza (1998) "Paradigmas, conceptos y relaciones para una nueva era. Cómo pensar las Ciencias Sociales desde América Latina", Seminario Las ciencias económicas y sociales: reflexiones de fin de siglo, Dirección de Estudios de Postgrado, Facultad de Ciencias Económicas y Sociales, Universidad Central de Venezuela, Caracas, 20 de junio de 1998 (mimeo). Citado en LANDER, Edgardo (Comp.) (2005) La colonialidad del saber: eurocentrismo y ciencias sociales. Perspectivas latinoamericanas. Buenos Aires, Argentina: Clacso, p. 27.

MOSCOVICl, Serge (1996). Psicología de las minorías activas. Madrid-España, Morata.

PÉREZ BENAVIDES, Isay (2010). La influencia religiosa en la conciencia social de Orlando Fals Borda. Barranquilla, Colombia, Corporación Universitaria Reformada.

SÁNCHEZ, Ricardo (2008). "Orlando Fals Borda: héroe cultural", en Ciencia Política, No. 6, Julio- Diciembre, 2008, pp. 9-17. Recurso electrónico disponible en: http://www.revistas.unal.edu.co. Consultado el 29 de octubre de 2013.
SOUSA SANTOS, Boaventura de (2009). Una epistemología del sur: la reinvención del conocimiento y la emancipación social. México, México: Siglo XXI - CLACSO.

Epistemología del sur y filosofía de la liberación. Conferencia en la UACM. Recurso electrónico disponible en: http://www.youtube.com/watch? $v=s s x d \_j 72 j X s \& f e a t u r e=y o u t u . b e$. Consul tado el 10 de noviembre de 2013.

VANEGAS MAHECHA, Samuel (2008). "Orlando Fals Borda, el legado del hacer ciencia", en Universitas Humanística, No. 66, julio-diciembre, 2008, pp. 13-18. Recurso electrónico disponible en: http://www.redalyc.org/articulo.oa?id=79 106602. Capturado el 28 de octubre de 2013.

VARSAVKSY, Óscar (1969/2007). Ciencia, política y cientificismo. Caracas, Venezuela: Monte Ávila Editores Latinoamericana.

VILLANUEVA MARTíNEZ, Orlando (1995). Camilo: acción y utopía. Bogotá, Colombia, Editorial Codice Ltda.

WRIGHT MILLS, Charles (1961/2003). La imaginación sociológica. México, México, Fondo de Cultura Económica. [Tercera edición]

\footnotetext{
'Ponencia presentada en el Congreso Internacional "Universidad en el Camino de la Innovación Pedagógica" realizado en Quito (Ecuador) del 21 al 22 de noviembre de 2013, y organizado por el Instituto Universitario de Educación Pedagógica de la Universidad Central del Ecuador. Agradecido el autor por el intercambio fecundo y maravilloso sostenido con los doctores Roberto Leher (Brasil) y Napoleón Saltos (Ecuador). Así mismo, agradece los maravillosos aportes, comentarios y correcciones de los historiadores Lorena López Guzmán y Carlos Andrés Celis Gómez y el teólogo Luis Hernán Peña, ofm. Finalmente al Mg. Tomás Quevedo Ramírez
} 
(Ecuador) por compartir su punto de vista sobre el encuentro entre la noción "Sentipensante" (de Orlando Fals Borda) y "corazonar" (de Patricio Guerrero Arias). 